\title{
Review Article \\ Health, Wellness, and Safety Aspects of the Consumption of Kombucha
}

\author{
Mindani I. Watawana, Nilakshi Jayawardena, \\ Chaminie B. Gunawardhana, and Viduranga Y. Waisundara \\ Functional Food Product Development Project, National Institute of Fundamental Studies, Hantane Road, 20000 Kandy, Sri Lanka \\ Correspondence should be addressed to Viduranga Y. Waisundara; viduranga@gmail.com
}

Received 10 September 2015; Revised 24 November 2015; Accepted 2 December 2015

Academic Editor: Tzortzis Nomikos

Copyright (c) 2015 Mindani I. Watawana et al. This is an open access article distributed under the Creative Commons Attribution License, which permits unrestricted use, distribution, and reproduction in any medium, provided the original work is properly cited.

\begin{abstract}
Functional foods have been identified as whole foods and fortified, enriched, or enhanced products which have a potentially beneficial effect on health when consumed as part of a varied diet on a regular basis, at effective levels. As consumer awareness on functional food escalates, the interest towards conducting scientific studies in this field has also proportionately increased. Many of the traditional food products are known to possess bioactive components, thus qualifying as functional food. Kombucha tea is produced by fermenting sugared black tea with a mixed culture of yeast and bacteria. Kombucha tea has gained immense popularity in recent times due to many associated health benefits. The therapeutic effects of this beverage are thought to be derived from the chemical composition of this beverage, mainly the polyphenols and secondary metabolites which are produced during fermentation. However, the safety aspects of the beverage also need to be taken into account when qualifying the beverage as a functional food. Nevertheless, Kombucha tea could be easily recognized as a beverage which is able to replace the consumption of carbonated beverages due to its possession of health benefits and therapeutic properties.
\end{abstract}

\section{Kombucha: Preparation and Fermentation Process}

Kombucha tea is known under different names throughout the world such as red tea fungus, Champignon de longue vie, Ling zhi, kocha kinoko, Chainii grib, and Chainii kvass [1]. It is traditionally prepared by fermenting sugared black tea with a symbiotic culture of yeast and bacteria. This beverage is thought to have originated in China over 2000 years ago [2], while there are many historical reports of this beverage being consumed in countries such as Russia, Germany, and the Middle East as well [3]. In many countries this beverage is produced in large-scale for commercial use as well as in domestic conditions. Despite being a fermented beverage, the flavor of Kombucha tea is considered to be satisfactory and nonacrimonious, though mildly acidic and mildly alcoholic, similar in taste to apple cider [4]. As the fermentation progresses, the taste of Kombucha tea changes from a pleasantly fruity, sour, lightly, and sparkling flavor to a mild vinegar-like taste, thus increasing the consumer acceptability of the flavor and other sensory aspects of the beverage $[4,5]$. The microbial composition of the Kombucha tea culture is known to vary from one culture to another depending on factors such as geographic location, climate, the local species of bacteria and yeast, and the source of the inoculum [6]. In some studies it has been proven that the use of different Kombucha starter cultures can cause a development of different antioxidant activity pathways even though the same substrate has been used [1,7].

The yeast and bacteria involved in this microbial fermentation form a mat-like pellicle known as a "tea fungus." The yeast component of this culture commonly consists of osmophilic yeast species, while the bacterial component includes acetic acid bacteria. In many studies it has been found that the dominant acetic acid bacterial species found in the microbial cultures are Acetobacter xylinum, A. xylinoides, A. aceti, A. pausterianus, and Bacterium gluconicum [5]. The dominant yeast strains were found out to be Kloeckera 


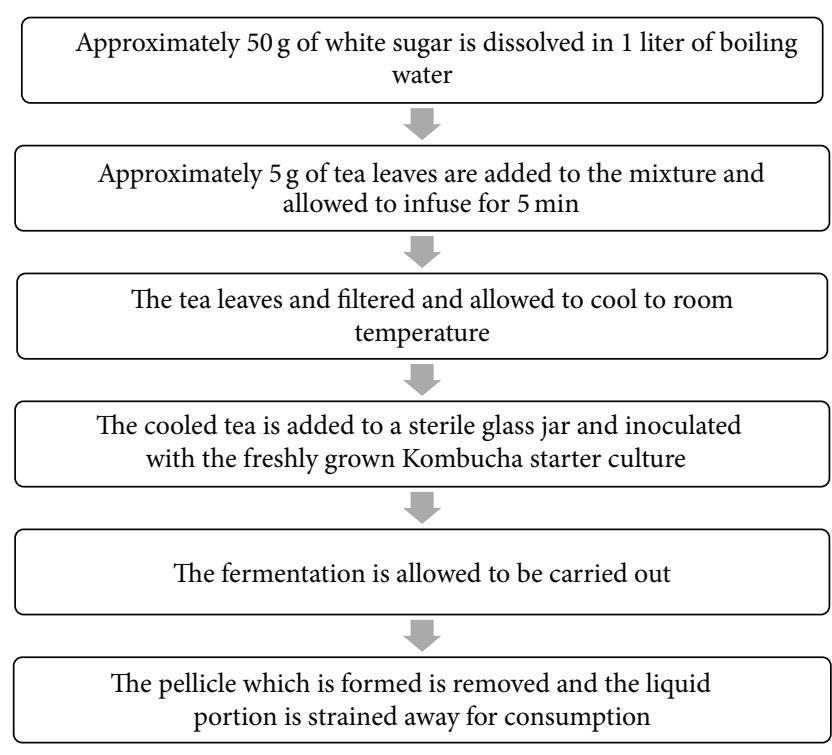

FIgURE 1: The typical method of preparation of the Kombucha beverages using sugared black tea.

spp., Schizosaccharomyces pombe, Saccharomyces ludwigii, S. cerevisiae, Torulaspora spp., Zygosaccharomyces bailii, and Pichia spp., [5]. The fungal-like structure is formed by the presence of these microbes in a zoogleal mat. This mat is produced due to the formation of a thin layer of floating cellulose to which the cell mass of bacteria and yeast is attached [6]. The cellulose is produced by the bacterial component of the microbial consortium. A. xylinum is primarily known to be responsible for the cellulose production and this cellulose network enhances the association between the bacteria and the fungi [8]. It has been reported that the caffeine and related xanthines found in tea have the ability to stimulate the synthesis of this cellulose production by the bacteria [8]. This powerful symbiotic association and its byproducts have the ability to inhibit the growth of potential contaminating bacteria [6]. The bacterial cell and yeast cell numbers are generally thought to reach $10^{4}-10^{6} \mathrm{cfu} \mathrm{mL}^{-1}$ in a Kombucha culture which has been allowed to ferment for a span of approximately 10 days [9]. Many scientific studies have proven that yeast outnumbers the bacterial count $[5$, 10]. As the fermentation progresses, the acidity of the broth increases due to the production of organic acids. Due to high acidity-induced oxygen starvation, the number of viable microbial cells present in Kombucha tea decreases as well [10]. The number of yeast and bacterial cells in the broth has been reported to be more than the cell number in the cellulosic pellicle [5].

In terms of the traditional preparation, the starter culture is added to a sugared black tea infusion and the fermentation is allowed to happen for a period of 3 to 10 days under ambient temperature [6]. A flow-chart containing the general preparation method is shown in Figure 1. Nevertheless, under domestic conditions of preparation, the amount of tea used for the fermentation process and the method of preparation differ according to personal preferences. The flavor and concentration of the compounds found in this beverage also differ with the starter culture, amount of starter culture used, type of tea, and type of sugar [6]. Even though traditionally black tea is being used as the substrate, Kombucha prepared by other substrates such as green tea and oolong tea are commonly available. Green tea has shown to have a better stimulation effect on the Kombucha fermentation compared with black tea fermentation and this leads to formation of the product in a shorter period of time [11, 12]. In some rare instances this beverage has been prepared by lemon balm tea, mulberry tea, jasmine tea, and peppermint tea $[6,11,13]$. The resulting broth is filtered out and the liquid portion is consumed. The tea fungus which is initially added to the tea is called the "mother tea fungus," where during the fermentation the development of a "daughter tea fungus" takes place. The cellulosic pellet rests on top of the tea broth and produces a fresh thin layer of the daughter mat which is available as a new layer above the old Kombucha culture mat. This new daughter mat is formed with each successful fermentation step, and it is used to reinoculate a new batch of tea. At the beginning of the fermentation, a small portion of previously prepared Kombucha broth may be added to the new tea to decrease the $\mathrm{pH}$ in order to stop the growth of undesired microorganisms [8]. As the fermentation progresses the appearance of gas bubbles will occur due to carbonic acid produced during the fermentation.

\section{Composition of Kombucha Tea and How It Differs from Black Tea}

The microbes in this culture are able to ferment the sugared black tea and produce a complex cocktail of molecules. At the end of the fermentation process, the resulting beverage would consist of sugars, polyphenols such as catechins, organic food acids, lysine, fiber, ethanol, amino acids, essential elements such as $\mathrm{Na}, \mathrm{K}, \mathrm{Ca}, \mathrm{Cu}, \mathrm{Fe}, \mathrm{Mn}, \mathrm{Ni}$, and $\mathrm{Zn}$, water-soluble vitamins such as vitamin $C$, vitamin $B$, and vitamin $B_{2}$, catalase, carbon dioxide, substances which act as antibiotic substances, and some hydrolytic enzymes $[1,14]$. The chemical structures of the commonly produced acids are shown in Figure 2. As the fermentation progresses, the yeast component of this mixed culture is able to break down sucrose to produce glucose, fructose, and carbon dioxide which gives off the effervescence and the sparkling appearance. The acetic acid bacteria have the ability to convert glucose to gluconic acid and fructose in to acetic acid. Also, the yeast component is able to produce ethanol which is then oxidized into acetaldehyde by the bacterial counterpart of this colony [15]. The yeast prefers fructose as the substrate when producing ethanol [8]. The acetic acid produced by the acetic acid bacteria has the ability to stimulate the production of ethanol by yeast, and ethanol in turn can facilitate the acetic acid bacteria to grow and produce acetic acid. The ethanol and acetic acid present in the Kombucha broth have been reported to be involved in the antimicrobial activity of the broth against pathogenic bacteria, thus providing a protection against contamination of the tea fungus [8]. It has been reported that even if the byproducts of the fermentation process decrease, the $\mathrm{pH}$ 
<smiles>O=C(O)[C@H]1OC(O)[C@H](O)[C@H](O)[C@@H]1O</smiles>

Glucuronic acid<smiles>O=C(O)C(=O)O</smiles>

Oxalic acid<smiles>O=C(O)C(O)C(O)C(O)C(O)CO</smiles>

Gluconic acid<smiles>C[C@H](O)C(=O)O</smiles>

L-lactic acid<smiles>O=C(O)CC(O)C(=O)O</smiles>

Malic acid<smiles>O=C(O)CC(O)(CC(=O)O)C(=O)O</smiles>

Citric acid

FIgURE 2: The most abundant organic acids found in Kombucha tea as a result of the fermentation process.

value of this beverage has a buffering capacity. This buffering capacity is due to carbon dioxide dissociation, and when this process happens, production of amphiprotic hydrocarbonate anion $\left(\mathrm{HCO}_{3}{ }^{-}\right)$occurs. This anion has the ability to react with hydrogen ions $\left(\mathrm{H}^{+}\right)$from organic acids and inhibit further change of $\mathrm{H}^{+}$concentration in the broth and thus contribute to formation of buffer in the system [16].

Even though Kombucha is based on the preparation of black tea, other than the fermentation process, it is considered different due to the chemical contents themselves. Tea (Camellia sinensis), in general, is one of the most popular beverages used worldwide and it has been consumed by many, for centuries. There are three major types of teas, namely, black, green, and oolong. Out of these three types, black tea is the most popular and it accounts for nearly $80 \%$ of the tea consumed worldwide [15]. This form of tea is prepared by the infusion of dried leaves of Camellia sinensis in hot water. The tea leaves, after picking, are air dried then crushed to release the enzymes and then allowed for enzymatic fermentation. Then, they are dried again to obtain the final product. Some of the main components of tea are purine alkaloids such as caffeine, theaflavins, gallotannins, triterpene, saponins, flavonoids, mineral compounds, carbohydrates, and vitamins $[15,16]$. Black tea is known to possess a higher radical scavenging property and the major contributor of this property is known to be polyphenols [17]. Depending on the geographical location, climate, season, soil fertility, and plantation method, a variation can be seen in this particular property [17]. Kombucha tea differs from its parental food by the antioxidant content, starch hydrolase inhibitory activity, anionic mineral composition, and acid content. Kumar et al. [18] have demonstrated the presence of the anionic minerals such as fluoride, chloride, bromide, iodide, phosphate, sulphate, and nitrate in both black and Kombucha tea. Table 1 shows a comparison of anionic mineral concentration of Kombucha tea and Black tea. They have further revealed that the anionic mineral compositions of Kombucha and black tea are significantly different from each
TABLE 1: Comparison of anionic mineral concentration of Kombucha tea and Black tea [7].

\begin{tabular}{lcc}
\hline Anion & Kombucha tea $(\mathrm{mg} / \mathrm{g})$ & Black tea $(\mathrm{mg} / \mathrm{g})$ \\
\hline $\mathrm{F}^{-}$ & $3.20 \pm 0.16$ & $1.20 \pm 0.06$ \\
$\mathrm{Cl}^{-}$ & $0.96 \pm 0.04$ & $3.12 \pm 0.13$ \\
$\mathrm{Br}^{-}$ & $0.04 \pm 0.01$ & $0.04 \pm 0.01$ \\
$\mathrm{NO}_{3}{ }^{-}$ & $0.18 \pm 0.01$ & $0.34 \pm 0.02$ \\
$\mathrm{HPO}_{4}{ }^{2-}$ & $0.04 \pm 0.01$ & $0.08 \pm 0.01$ \\
$\mathrm{SO}_{4}{ }^{2-}$ & $1.02 \pm 0.04$ & $4.20 \pm 0.17$ \\
$\mathrm{I}^{-}$ & $1.04 \pm 0.08$ & $0.44 \pm 0.04$ \\
\hline
\end{tabular}

other [18]. Kombucha tea is known to exhibit an increase in the radical scavenging properties during the fermentation possess, showing a higher antioxidant capacity than black tea [19].

\section{Health Benefits Associated with Consumption of Kombucha}

The American Diabetic Association has defined functional food to be products including whole foods and fortified, enriched, or enhanced foods, which have a potentially beneficial effect on health when consumed as part of a varied diet on a regular basis, at effective levels [20]. Kombucha beverage is known to possess many prophylactic and therapeutic benefits; it is believed to help in digestion, give relief against arthritis, act as a laxative, prevent microbial infections, combat stress and cancer, provide relief against hemorrhoids, impart a positive influence on the cholesterol levels, and facilitate excretion of toxin as well as blood cleansing [1, $6,8]$. This beverage is also associated with influencing the gastrointestinal microbial flora in humans by acting as a probiotic drink and helping in balancing the intestinal flora, thus facilitating the normalization of intestinal activities to a certain extent $[1,21,22]$. It is also known to have the 
TABLE 2: Some constituents of Kombucha related to health claims and their recommended values for consumption.

\begin{tabular}{|c|c|c|c|c|}
\hline Chemical constituent & $\begin{array}{l}\text { Amount present in } \\
\text { Kombucha green tea } \\
(\mathrm{g} / \mathrm{L})\end{array}$ & $\begin{array}{l}\text { Amount present in } \\
\text { Kombucha black tea } \\
(\mathrm{g} / \mathrm{L})\end{array}$ & $\begin{array}{l}\text { Recommended maximum level as per } \\
\text { standard guidelines }\end{array}$ & $\begin{array}{l}\mathrm{LD}_{50} \text { value in rats via } \\
\text { oral route (mg/kg of } \\
\text { body weight) }\end{array}$ \\
\hline Acetic acid & $\begin{array}{c}9.51 \pm 0.35 \text { (on day } 15) \\
{[33]}\end{array}$ & $\begin{array}{c}6.17 \pm 0.3(\text { on day } 15) \\
{[33]}\end{array}$ & 2.1 g per day $[62]$ & $3310[63]$ \\
\hline Glucuronic acid & $1.57 \pm 0.14$ (on day 15$)$ & $\begin{array}{c}1.5 \pm 0.17 \text { (on day } 15) \\
{[33]}\end{array}$ & Not available & Not available \\
\hline Lactic acid & $\begin{array}{c}0.15 \pm 0.02(\text { on day } 15) \\
{[33]}\end{array}$ & $\begin{array}{c}0.33 \pm 0.07 \text { (on day } 15) \\
{[33]}\end{array}$ & $\begin{array}{l}\text { FDA requirement substance added } \\
\text { directly to the human food affirmed as } \\
\text { generally recognized as safe (GRAS) } \\
\text { [64] }\end{array}$ & $3730[65]$ \\
\hline Citric acid & Not available & Not available & $3000 \mathrm{mg} / \mathrm{kg}$ per day [66] & $3000[67]$ \\
\hline Oxalic acid & 0.03 (on day 3 ) [33] & 0.11 (on day 3 ) [33] & $\begin{array}{l}0.14 \mathrm{mg} / \mathrm{kg} \text { per day (the scientific basis } \\
\text { for this conclusion is not available and } \\
\text { therefore no safe dietary dose for } \\
\text { oxalic acid can be established) [68] }\end{array}$ & $7500[69]$ \\
\hline Acetaldehyde & Not available & Not available & $0-2.5 \mathrm{mg} / \mathrm{kg}$ per day $[70]$ & $661[71]$ \\
\hline
\end{tabular}

ability to improve the health of hair, skin, and nails, reduce stress and nervous disturbances, reduce insomnia, relieve headaches, reduce the craving for alcohol of an alcoholic person, and prevent the formation of bladder infections $[6,8]$. Reducing the kidney calcification is also known to be a beneficial effect of this beverage [6]. Reduction of menstrual disorders and menopausal hot flashes, improving eye sight, cellular regeneration, stimulation of glandular systems in the body, relieving bronchitis and asthma and the enhancement of general metabolism are a few more of the health benefits which have been claimed to be associated with consumption of the Kombucha broth [6]. The beneficial effects of this beverage are known to be attributed to the presence of the metabolic products released into the broth during the fermentation, although most of the health benefits are hypothesized to be due to its radical scavenging potential. The microbial community has the ability to enhance the radical scavenging activity of black tea by the fermentation process [8]. Also, the presence of glucuronic acid imparts beneficial properties to this drink [9]. Glucuronic acid is normally produced by a healthy liver and is a highly water soluble carboxylic acid. This acid can be converted into glucosamine and chondroitin-sulfate which are associated with collagen and also the fluid that acts as lubricate in the joints [23]. Butyric acid produced by the microbial consortium in the fermentation process is known to protect human cellular membranes. In combination with glucuronic acid, this complex has the ability to strengthen the walls of gut and give protection against parasites [8]. Table 2 shows some of the constituents of Kombucha related to health claims and their recommended values for consumption. Although it may appear that many reports which are available on Kombucha are based on personal experiences and testimonials, in recent times, scientists have provided scientific evidence elucidating the therapeutic effects of the beverage from in vitro as well as in vivo studies. Table 3 shows the bioactivities of Kombucha and the mode of studies which have been carried out. However, in contrast to the number of studies done on other fermented products such as fermented milk, the amount of studies done on this beverage is very low. Nevertheless, the subsequent sections of this review summarize the purported health benefits of Kombucha based on available scientific evidence and reports. In addition, given the fermentation process involved in producing the beverage, the review also summarizes the safety issues and aspects of caution which need to be borne in mind when consuming the beverage.

3.1. Antimicrobial Activity. Kombucha tea is known to show a remarkable antimicrobial activity against a broad range of microorganisms. Many scientific studies have been done on this subject and the Kombucha broth has demonstrated inhibitory activity against many pathogenic microorganisms of both Gram positive and Gram negative origin [8]. Kombucha tea has demonstrated the ability to inhibit the growth of pathogens such as Helicobacter pylori (the causative organism of peptic ulcers), Escherichia coli (the causative organism of common diarrhea), Entamoeba cloacae, Pseudomonas aeruginosa, Staphylococcus aureus, Staphylococcus epidermis, Agrobacterium tumefaciens, Bacillus cereus, Aeromonas hydrophila, Salmonella typhimurium, Salmonella enteritidis, Shigella sonnei, Leuconostoc monocytogenes, Yersinia enterocolitica, Campylobacter jejuni, and Candida albicans [8, 24, 25]. This antimicrobial activity of the broth is attributed to the low $\mathrm{pH}$ value of this beverage, especially owing to the presence of acetic acid in particular and a range of other organic acids and catechins which are shown in Figure 2 as well as many large proteins which are produced during the fermentation $[8,24]$. Acetic acid and catechins are specially known to inhibit a range of Gram positive and Gram negative microorganisms [6]. It has also been demonstrated that the broth may contain antibiotic substances which give the antimicrobial property [24, 26]. Some studies have demonstrated that Kombucha tea shows not only antibacterial activity but also antifungal activity [27]. The antifungal activity is attributed to the production and 
TABLE 3: Bioactivities of Kombucha and mode of studies which have been carried out.

\begin{tabular}{ll}
\hline Bioactivities & References \\
\hline Antihypercholesterolemic effect & In vitro studies on rats [33] \\
Antioxidant activity against chromate & In vivo studies on rats [47] \\
Antioxidant activity against lead & In vivo studies on rats [3] \\
Antistress activity against cold and hypoxia & In vivo studies on rats [46] \\
Cytogenetic activity & In vitro studies on human peripheral blood \\
Healing activity against indomethacin-induced acute & lymphocytes [72] \\
gastric ulceration & In vivo studies on mice [50] \\
$\begin{array}{l}\text { Hypoglycaemic effect } \\
\text { Inhibitory activity towards CCl }{ }_{4} \text { induced hepatic injury }\end{array}$ & In vivo studies on mice [6, 73] \\
Longevity & In vivo studies on rats [45] \\
$\begin{array}{l}\text { Paracetamol induced hepatotoxicity } \\
\text { Prevention of weight loss in diabetes }\end{array}$ & In vivo studies on mice [74] \\
$\begin{array}{l}\text { Protective effect on chromosomal aberrations induced by } \\
\text { gamma radiation in human peripheral lymphocytes }\end{array}$ & In vivo studies on mice [47] \\
\hline
\end{tabular}

presence of acetic acid in this beverage. In recent times, the immergence of resistant strains of pathogens associated with human diseases has been widely seen, and the use of Kombucha tea as an antimicrobial product can be used to overcome this problem [27]. In this aspect, it has been demonstrated that the antimicrobial activity of Kombucha tea prepared form green tea shows a higher activity than Kombucha tea prepared traditionally from black tea [27].

3.2. Probiotic Effects. Probiotics are known to be living microorganisms; when administrated in adequate amounts, they are able to result in health benefits. Most often, the bacterial component of a probiotic mixture comes from Lactobacillus or Bifidobacterium or a cocktail of these two strains. In support of these lines, there can be a few common yeast types such as Saccharomyces boulardii and S. cerevisiae in this mixture as well [14]. Probiotic microbes are known to play a vital role in the wellness of human health. Probiotic microorganisms provide a balance in intestinal microbiota, normalizing processes in gut and boosting the immune system. In addition, they help in improving digestion, fighting against harmful bacterial overgrowths, and achieving mental clarity and mood stability and against psychological conditions such as anxiety and depression. Many studies have claimed that this beverage not only is a probiotic but also acts as a symbiotic, a combination of prebiotics and probiotics $[8,21]$. A prebiotic selectively helps the growth and activity of the consortium of beneficial microbes present in the human gut [21]. The bacteria and yeast present in this beverage act as probiotics and the microcellulose which is present can help in the growth of the beneficial microbes present in the intestine [14]. The popularity of this beverage as a probiotic and a synbiotic has increased in recent times as scientists have found that this beverage can be used to give the required nutrition and help maintain health and wellness in humans who work under unhealthy environments, such as workers in mines and polar expeditors [14]. When the human body is exposed to such conditions for a prolonged period of time, the normal microbial consortium of microbes in the intestine changes due to the unnatural conditions, psychoemotional discomfort, and drastic change in the diet. This may lead to the disappearance of the protective gut microbes and the immergence of harmful secondary infections by opportunistic microbes. This shift in the gut microbiota can lead to many health issues such as allergies, autoimmune diseases, multiple sclerosis, and transplant infectious disease. The change in the gut microbiota can be corrected to some extent with the help of Kombucha tea. In light of these mentioned possibilities, scientists have started to consider this beverage to be used by astronauts as a supplement to their diet in outer space [14].

3.3. Anticancer Properties. Dietary phytochemicals have been identified as effective anticancer agents. Thus, there is a recent trend of consuming food rich in these bioactive compounds. Scientific studies have claimed that Kombucha has anticancer effects as well [8]. The Central Oncological Research Unit in Russia and the Russian Academy of Sciences in Moscow have conducted population studies on this fermented beverage and have found that the daily consumption of Kombucha broth has a correlation with an extremely high resistance to cancer [8]. Scientists have come up with many possible mechanisms for the anticancer ability of this beverage. For instance, it has been reported that the ability of this fermented beverage to act as an anticancer agent is due to the presence of tea polyphenols and the secondary metabolites produced during the fermentation process $[6,28]$. Many studies have shown that the ability of the tea polyphenols present in this fermented beverage to inhibit gene mutations, inhibit the proliferation of cancer cells, and induce cancer cell apoptosis and the ability to terminate metastasis have been highlighted 
as possible mechanisms for the anticancer properties [2931]. It has also been noted that the consumption of Kombucha tea can help cancer patients to reequilibrate blood $\mathrm{pH}$ which usually increases more than 7.56 in the course of the illness. Additionally, cancer patients lack L-lactic acid in their connective tissues; this can also be corrected by the consumption of Kombucha, where the fermentation process produces lactic acid as a byproduct [8]. Many of the compounds which were identified to be present in Kombucha tea such as polyphenols, gluconic acid, glucuronic acid, lactic acid, and vitamin $\mathrm{C}$ are known to have the ability to reduce the occurrence of stomach cancer. It has also been found out that Kombucha contains D-saccharic acid-1,4-lactone (DSL) which is known to inhibit the activity of glucuronidase, an enzyme which is thought to be indirectly related to cancer [26]. Glucuronidase has the ability to hydrolyze glucuronide and produce cancer-causing aglycones [32]. It was reported that the polyphenols present in the Kombucha tea possess antitumor properties, thus acting as a cancer-blocking agent [26]. Another study reports presence of dimethyl2(2-hydroxy-2-methoxypropylidene) malonate and vitexin in the ethyl acetate fraction of Kombucha tea which has shown cytotoxic effects at a concentration of $100 \mu \mathrm{g} / \mathrm{mL}$ [28].

3.4. Detoxification. Detoxification is the complex process of removal of toxic substances from the body of a living organism. This process can be physiological or medicinal. In the human body, this process is carried out mainly by the liver. Detoxification helps in the maintenance of a healthy liver and is also known to play a part in cancer prevention. The enzymes, bacterial acids, and other secondary metabolites produced by the microbes during the fermentation process done in the preparation of Kombucha tea have displayed the ability to detoxify body [8]. In addition, most of the enzymes and bacterial acids found in Kombucha tea are very similar to the chemicals produced by the body for the purpose of the detoxifying process. Thus, incorporation of Kombucha tea into one's diet may result in the reduction of the detoxification load pressured on the liver. Many scientific studies have reported that this ability is mainly due to the capacity of glucuronic acid to bind with toxic molecules which enter the body and also the ability to increase excretion of these molecules from the physiology by the help of kidneys and intestines [33]. The process of strong binding between the glucuronic acid molecules and the toxin is known as glucuronidation [34]. Glucuronic acid is produced due to the oxidation process of glucose during the fermentation process [34]. This acid is the most significant detoxifier in human body; thus, it has the ability to bind to the toxins in the liver and encourage them to flush out of the body [35]. Similar to glucuronic acid, malic acid is also a byproduct of the fermentation which helps in detoxifying the liver [2]. Other than supporting the detoxification of the liver, consumption of Kombucha tea is also known to help excrete heavy metal substances and environmental pollutants from the human body through the kidneys [9]. It is also beneficial in the biotransformation of indigenous metabolites such as bilirubin and excess of steroid hormones [2]. The toxin removal action of Kombucha tea is known to help in obtaining relief from gout, rheumatism, arthritis, and kidney stones which are conditions associated with the accumulation of toxic substances in the body [8].

3.5. Antioxidant Activity. The popular definition of an antioxidant is any substance, when present at low concentrations compared with that of an oxidizable substrate, that significantly delays or inhibits oxidation of the substrate [36]. This bioactivity could be broadly presented in the form of (1) scavenging properties of molecules, (2) binding of prooxidant metals, and (3) inhibition of prooxidant enzymes. Many studies have proven the effect of these antioxidant properties on many human diseases such as cancer and diabetes [7]. The primary mechanism of the action of antioxidants in these disease conditions is to remove free radical intermediates, and these free radicals are generated in oxidation reactions which happen across the human body. Free radicals have the ability to start multiple chain reactions which will eventually lead to cell damage or the death of the affected cell [36]. When an antioxidant comes in contact with free radicals, they have the ability to oxidize themselves and inhibit other oxidation reactions which lead to harmful chain reactions. The oxidative stress caused by free radicals plays an important role in many of the commonly prevalent human diseases such as Parkinson's disease, coronary heart disease, and cancer, the reasons being the lack of appropriate nutrition and exercise, air pollution in the environment, and smoking [2]. In order to counterbalance this oxidative stress caused by free radicals, it is important to incorporate antioxidant containing food stuff to the daily diet [36].

During the Kombucha fermentation, many compounds with radical scavenging properties are released from the tea leaves themselves [1]. Polyphenols and catechins are the main group of compounds which are found in tea belonging to flavanol group [1, 27, 37]. Polyphenols are considered as having high levels of broad antioxidant properties since they have the ability to scavenge free radicals and reactive oxygen species (ROS) [2]. Polyphenols are about $30 \%$ of the total dry weight of fresh tea leaves and epigallocatechin, epigallocatechin-3-gallate, epicatechin-3-gallate, and epicatechin are the most prominent types of polyphenols found in tea leaves [19]. Kombucha tea when prepared using green tea, black tea, and tea waste material has been shown to have a high radical scavenging activity [19]. When the complex phenolic compounds are present in an acidic environment or when enzymes liberated by bacteria and yeasts in tea fungus are present, degradation of complex molecules to small molecules happens and this causes an increase in the total phenolic compounds available in the Kombucha tea broth [2]. Therefore, when the fermentation happens, the total phenolic content increases [2]. The production of compounds possessing radical scavenging properties depends on the culture period and starter origins where they decide which metabolites are to be produced [7]. However, prolonged fermentation is not suitable as accumulation of organic acids can cause a harmful effect when Kombucha tea is directly consumed [2]. 
3.6. Hepatoprotective Effects. Hepatoprotection is the ability to prevent the damage occurring to the liver by toxic substances $[22,38]$. Many studies carried out on cell lines and animal models have shown that Kombucha broth shows hepatoprotective activity against various environmental pollutants [6]. Many of the environmental pollutants have the ability to induce hepatotoxicity and damage the liver. Many scientific studies were carried out to assess the ability of this tea broth to effectively attenuate the physiological changes which are caused by many of the hepatotoxicity-causing agents such as aflatoxin B1 [39], cadmium chloride [40], tert-butyl hydroxyperoxide [41], and acetaminophen [42, 43]. Carbon tetrachloride $\left(\mathrm{CCl}_{4}\right)$ is a xenobiotic that induces the lipid peroxidation and it forms a free radical $\mathrm{CCl}_{3}{ }^{-}$, and this involves accumulating lipid derived oxidants which leads to liver injury [44]. Kombucha tea consumption has been demonstrated to inhibit the activity of $\mathrm{CCl}_{4}$ and prevent liver injury in rats [45]. In vivo studies have suggested that Kombucha tea is capable of preventing paracetamol induced hepatotoxicity [46]. Studies have been carried out to investigate how Kombucha tea can induce oxidative stress in Albino rats by chromate (VI) [47]. Studies have also been carried out to find protective effects of Kombucha tea against thioacetamide-induced hepatotoxicity and the results have shown that the antioxidant activity of polyphenol substances of Kombucha tea is responsible for this function [22]. These studies have further explained that Kombucha tea prevents the apoptotic cell death of the hepatocytes which is triggered from the exposure of the liver to the environmental toxins [22]. Histological analyses of alloxaninduced diabetes rats given a diet containing Kombucha tea have revealed protective liver-kidney functions [48]. This is supported by the reduction in the activity of aspartate transaminase, alanine transaminase, and gamma-glutamyl transpeptidase in the plasma, as well as in the creatinine urea concentrations [48]. Pathophysiological evidences are also available for hepatoprotective effects of Kombucha tea in rat models [41, 43].

3.7. Other Therapeutic Effects. There are many allegations of health benefits and uses related to this beverage, some of which are not discussed in this review in further detail. For instance, the microbial mat produced in the fermentation had been used to produce artificial skin in Nossa Senhora da Conceição Hospital from Lagarto, SE, Brazil [49]. Some researchers have used this skin to accelerate the healing process and also as an antiseptic by adhering it to open injuries, the so-called Bioskin [49]. The bacterial cellulose which is produced during the Kombucha tea fermentation process has many potential applications in fields such as food and biopharmaceuticals. The ability and trend to use bacterial cellulose in these fields are due to the high purity and the unique physicochemical properties which are present in the fermented beverage. In addition, this bacterial cellulose is preferred in instances where plant based cellulose cannot be used [5]. In the food industry bacteria-based cellulose is used as food matrices, thickeners, dietary fibers, stabilizes, and binders [5]. Lactic acid is one of the organic acids produced during the Kombucha tea fermentation. It is able to enhance the blood circulation and helps prevent constipation [8]. Oxalic acid, which is also produced as a byproduct, can be useful in the production of adenosine triphosphate (ATP) [6]. Bacteria found in the Kombucha mat produce gluconic acid by breakdown of caprylic acid which can prevent certain types of yeast-based infections and candidiasis [33]. Butyric acid is a production of yeast available in the Kombucha mat and helps in protecting the human cellular membrane, where it combines with gluconic acid and strengthens the gut walls in conditions such as candidiasis [6]. Moreover, healing of gastric ulcers in rats due to Kombucha tea has been evident as per histopathological and biochemical studies [50]. The usage of this beverage to eliminate the growth of gray hair and the usage in the improvement of eyesight are a few of the health benefits which have been claimed as well [8]. Oral supply of Kombucha tea at a dose of $5 \mathrm{mg} / \mathrm{kg}$ of body weight in alloxan-induced diabetes rats has depicted better inhibition on $\alpha$-amylase and lipase enzyme activity in the plasma and pancreas and also better suppression of increased blood glucose levels [48]. Thus, Kombucha tea has potential hypoglycemic and antilipidemic activity as well.

\section{Safety Issues and Controlling Potential Hazards of Kombucha}

Since Kombucha is a complex mixture of microorganisms, it is essential to discuss the safety of Kombucha tea for consumption. As mentioned previously, bacteria and fungi in the Kombucha zoogleal mat are capable of forming a powerful symbiosis which can inhibit the growth of contaminating bacteria $[8,51]$. Nevertheless, pathogenic microorganisms can contaminate the Kombucha tea throughout the preparation. Due to fermentation, the $\mathrm{pH}$ reaches $\leq 4.2$. However, until this is achieved, there is a high possibility for contaminations to occur [52]. Mold contamination can occur on Kombucha cultures, especially with Penicillium and Aspergillus, when the Kombucha tea is home-made. Aspergillus species are known to cause carcinogenic and toxigenic effects [53]. Therefore, it is important to be cautious when administering infected beverages by immunecompromised individuals. It is essential to concern that that the efficacy of Kombucha tea as a therapeutic beverage is hardly proven by clinical trials involving human subjects [54]. Beside, even though consumption of Kombucha claims to have no adverse side effects, there have been a few exceptions over past years. Few case reports and case series question the safety of Kombucha tea with suspected liver damage, metabolic acidosis, and cutaneous anthrax infections [54]. Allergic reactions and an uncomfortable stomach are a result of consuming Kombucha tea by people with acid sensitivities and renal insufficiencies [53]. Several studies have confirmed that Kombucha can cause nausea, shortness of breath, throat tightness, headache, dizziness, and jaundice $[34,53]$. One case revealed that two persons had developed allergic reactions, a third person developed jaundice, and another developed nausea, vomiting, and head and neck pain. The case reports an etiological association of all four patients since all of them 
had consumed Kombucha tea in proximity to the onset of symptoms and their subsequent disappearance after cessation of drinking the beverage [55]. Some individuals have reported that they felt dizziness and nausea after consumption of Kombucha tea [56]. However, it was not explained whether these symptoms are a result of unusual toxins developed in a particular batch of Kombucha tea.

Overfermentation can increase the availability of high acetic acid concentrations, and this might lead to the leeching of some chemical contaminants from the fermentation vessel or packaging materials. There is evidence that severe lead poisoning can be caused by regular use of Kombucha tea which was brewed in a ceramic pot $[57,58]$. This might have occurred due to Kombucha tea being acidic and the resulting reactions caused by some ceramics. Most of the ceramics contain very low levels of lead which would not be of any danger when brewing Kombucha tea. Nevertheless, if the Kombucha is steeped in them for a long time, then high amounts of lead can dissolve in the tea $[6,57]$. It is important to use glass containers for the preparation and storage of Kombucha tea to prevent leaching of toxic elements such as lead into the beverage. In addition to acetic acid, Kombucha tea contains several organic acids $[6,33]$. Some of these metabolites have the potential to damage liver and kidney at high concentrations, as evident by few case reports $[56,59,60]$. Kombucha tea is contraindicated in pregnant and lactating women [53]. Studies have also reported the presence of Bacillus anthrax in Kombucha tea fermented under unhygienic conditions [61]. The source of B. anthrax was found to be cows and anthrax was passed to an individual who rubbed it on his skin to alleviate the pain.

Due to the detoxification effects of Kombucha tea, toxic materials are forced to be excreted from the body. However, if the kidneys are not working properly, these individuals may not be able to successfully discharge the toxic materials. Thus, it is recommended to drink plenty of water to facilitate the elimination of toxins to overcome this problem [53]. From this aspect, it is essential to give attention to the abnormal odour or colour development in Kombucha tea to overcome any adverse side effects. Domestic cultivation of Kombucha is one of the most possible ways of contamination by pathogenic bacteria and yeasts. Since this tea fungus is being grown under aseptic conditions and it is propagated from one house to another, the transfer of contaminations is high $[13,53]$. A study reported that consumption of Kombucha might also be a health risk for HIV-positive patients [6]. It was discovered that acute renal failure may occur with lactic acidosis and hyperthermia due to consumption of this beverage. The possibility of getting infected by toxins is higher when Kombucha tea is consumed in large quantities. Another report states that one individual died due to perforations of the intestinal tract and severe acidosis, who consumed home-made Kombucha tea $4 \mathrm{oz}$ per day for two months [52]. Another individual who consumed Kombucha tea coming from the same initial zoogleal mat had suffered from cardiac arrest and severe acidosis [52]. Despite these reports, most of these studies are limited to a very small number of individuals. Hence, further studies should be carried out to form a substantial conclusion about the safety aspects in the consumption of Kombucha tea.

Using clean and sanitized utensils during preparation of Kombucha tea helps in preventing any contamination. It is better to keep the preparation and fermentation areas clean to control growth of any microorganisms since tea must be cooled to about $20^{\circ} \mathrm{C}$ within two hours prior to adding the Kombucha culture into the tea. It is also important to control the $\mathrm{pH}$ during the fermentation process since overproduction of acetic acid can be hazardous. According to the British Columbia Center for disease control, the fermentation should be terminated at the $\mathrm{pH} 4.2$ [56]. Overproduction of alcohols and carbon dioxide can also be prevented by pasteurizing the finished product [57]. Adding $0.1 \%$ sodium benzoate and $0.1 \%$ potassium sorbate to the finished product, followed by refrigeration, can also be carried out for safety purposes [61]. Refrigeration of the final product is the most common method followed by the commercial producers of Kombucha tea [13].

\section{Conclusions}

The chemical composition of the Kombucha tea depends on type of tea leaf variety, amount of sugar, and fermentation and composition of tea fungus. However, there are a very few studies focused on the safety of consuming Kombucha tea. Most of the health properties of Kombucha are related to the acidic composition of the beverage and acetic acid, which is the major acidic component to inhibit the fungal growth. Overproduction of acids can be controlled during the fermentation duration as well as the packaging of the final product. Yet, the importance of studying the safety of Kombucha tea consumption is important as there are only a very few such studies been carried out throughout the years. Since this a popular beverage around the world, investigating the advantages and disadvantages of consuming this beverage in similar capacities can be extremely meaningful. According to literature, there is no evidence about systematic human trials being done using Kombucha tea. This could be an area in which future research could be focused in establishing this beverage as a functional food. Since studies carried out to assess qualitative and quantitative properties of constituents of Kombucha are scattered, scientific research should be carried out to clarify the health beneficial claims and safety aspects, which might help in promoting this beverage among consumers. Despite the scattered safety issues, production and consumption of this beverage in a safe manner can be used to substantiate the stand of this beverage as a replacement for carbonated beverages. Attention of relevant authorities should be focused on establishing national and international policies and regulations regarding the safety of Kombucha consumption and mass production of this beverage as a readily available commercial beverage.

\section{Conflict of Interests}

The authors declare that there is no conflict of interests regarding the publication of this paper. 


\section{Acknowledgments}

The authors wish to acknowledge the financial support rendered by the National Institute of Fundamental Studies, Hantane Road, Kandy, Sri Lanka. Funding provided for Mrs. Chaminie B. Gunawardhana as a research student through National Research Council of Sri Lanka, Grant no. 14-13, is also acknowledged.

\section{References}

[1] R. V. Malbaša, E. S. Lončar, J. S. Vitas, and J. M. ČanadanovićBrunet, "Influence of starter cultures on the antioxidant activity of kombucha beverage," Food Chemistry, vol. 127, no. 4, pp. 17271731, 2011.

[2] T. Srihari and U. Satyanarayana, "Changes in free radical scavenging activity of Kombucha during fermentation," Journal of Pharmaceutical Sciences and Research, vol. 4, no. 11, pp. 19781981, 2012.

[3] P. Dipti, B. Yogesh, A. K. Kain et al., "Lead induced oxidative stress: beneficial effects of Kombucha tea," Biomedical and Environmental Sciences, vol. 16, no. 3, pp. 276-282, 2003.

[4] A. J. Marsh, O. O'Sullivan, C. Hill, R. P. Ross, and P. D. Cotter, "Sequence-based analysis of the bacterial and fungal compositions of multiple kombucha (tea fungus) samples," Food Microbiology, vol. 38, pp. 171-178, 2014.

[5] W. N. Goh, A. Rosma, B. Kaur, A. Fazilah, A. A. Karim, and R. Bhat, "Fermentation of black tea broth (Kombucha): I. Effects of sucrose concentration and fermentation time on the yield of microbial cellulose," International Food Research Journal, vol. 19, no. 1, pp. 109-117, 2012.

[6] R. Jayabalan, R. V. Malbaša, E. S. Lončar, J. S. Vitas, and M. Sathishkumar, "A review on kombucha tea-microbiology, composition, fermentation, beneficial effects, toxicity, and tea fungus," Comprehensive Reviews in Food Science and Food Safety, vol. 13, no. 4, pp. 538-550, 2014.

[7] S.-C. Chu and C. Chen, "Effects of origins and fermentation time on the antioxidant activities of Kombucha," Food Chemistry, vol. 98, no. 3, pp. 502-507, 2006.

[8] C. Dufresne and E. Farnworth, "Tea, Kombucha, and health: a review," Food Research International, vol. 33, no. 6, pp. 409-421, 2000.

[9] A. L. Teoh, G. Heard, and J. Cox, "Yeast ecology of Kombucha fermentation," International Journal of Food Microbiology, vol. 95, no. 2, pp. 119-126, 2004.

[10] C. Chen and B. Y. Liu, "Changes in major components of tea fungus metabolites during prolonged fermentation," Journal of Applied Microbiology, vol. 89, no. 5, pp. 834-839, 2000.

[11] A. S. Velićanski, D. D. Cvetković, S. L. Markov, V. T. Tumbas, and S. M. Savatović, "Antimicrobial and antioxidant activity of lemon balm Kombucha," Acta Periodica Technologica, vol. 38, pp. 165-172, 2007.

[12] C. J. Greenwalt, R. A. Ledford, and K. H. Steinkraus, "Determination and characterization of the antimicrobial activity of the fermented tea Kombucha," LWT_Food Science and Technology, vol. 31, no. 3, pp. 291-296, 1998.

[13] A. Velićanski, D. Cvetković, and S. Markov, "Characteristics of kombucha fermentation on medicinal herbs from lamiaceae family," Romanian Biotechnological Letters, vol. 18, no. 1, pp. 8034-8042, 2013.
[14] N. O. Kozyrovska, O. M. Reva, V. B. Goginyan, and J.-P. De Vera, "Kombucha microbiome as a probiotic: a view from the perspective of post-genomics and synthetic ecology," Biopolymers and Cell, vol. 28, no. 2, pp. 103-113, 2012.

[15] A. Morshedi and M. H. Dashti-Rahmatabadi, "Chronic consumption of Kombucha and black tea prevents weight loss in diabetic rats," Iranian Journal of Diabetes and Obesity, vol. 2, no. 2, pp. 23-26, 2010.

[16] D. Kaczmarczyk and S. Lochyński, "Products of biotransformation of tea infusion-properties and application," Polish Journal of Natural Sciences, vol. 29, no. 4, pp. 381-392, 2004.

[17] S. Jayasekera, A. L. Molan, M. Garg, and P. J. Moughan, "Variation in antioxidant potential and total polyphenol content of fresh and fully-fermented Sri Lankan tea," Food Chemistry, vol. 125, no. 2, pp. 536-541, 2011.

[18] S. D. Kumar, G. Narayan, and S. Hassarajani, "Determination of anionic minerals in black and Kombucha tea using ion chromatography," Food Chemistry, vol. 111, no. 3, pp. 784-788, 2008.

[19] R. Jayabalan, P. Subathradevi, S. Marimuthu, M. Sathishkumar, and K. Swaminathan, "Changes in free-radical scavenging ability of kombucha tea during fermentation," Food Chemistry, vol. 109, no. 1, pp. 227-234, 2008.

[20] C. M. Hasler, A. S. Bloch, and C. A. Thomson, "Position of the American Dietetic Association: functional foods," Journal of the American Dietetic Association, vol. 104, no. 5, pp. 814-826, 2004.

[21] R. J. S. Júnior, R. A. Batista, S. A. Rodrigues, L. X. Filho, and Á. Silva Lima, "Antimicrobial activity of broth fermented with Kombucha colonies," Journal of Microbial \& Biochemical Technology, vol. 1, no. 1, pp. 72-78, 2009.

[22] N. Kabiri, M. Setorki, and M. A. Darabi, "Protective effects of Kombucha tea and silimarin against thioacetamide induced hepatic injuries in wistar rats," World Applied Sciences Journal, vol. 27, no. 4, pp. 524-532, 2013.

[23] N. Yavari, M. M. Assadi, M. B. Moghadam, and K. Larijani, "Optimizing Glucuronic acid production using tea fungus on grape juice by response surface methodology," Australian Journal of Basic and Applied Sciences, vol. 5, no. 11, pp. 17881794, 2011.

[24] G. Sreeramulu, Y. Zhu, and W. Knol, "Kombucha fermentation and its antimicrobial activity," Journal of Agricultural and Food Chemistry, vol. 48, no. 6, pp. 2589-2594, 2000.

[25] G. Sreeramulu, Y. Zhu, and W. Knol, "Characterization of antimicrobial activity in Kombucha fermentation," Acta Biotechnologica, vol. 21, no. 1, pp. 49-56, 2001.

[26] M. Deghrigue, J. Chriaa, H. Battikh, K. Abid, and A. Bakhrouf, "Antiproliferative and antimicrobial activities of Kombucha tea," African Journal of Microbiology Research, vol. 7, pp. 34663470, 2013.

[27] H. Battikh, K. Chaieb, A. Bakhrouf, and E. Ammar, "Antibacterial and antifungal activities of black and green kombucha teas," Journal of Food Biochemistry, vol. 37, no. 2, pp. 231-236, 2013.

[28] R. Jayabalan, P.-N. Chen, Y.-S. Hsieh et al., "Effect of solvent fractions of kombucha tea on viability and invasiveness of cancer cells-characterization of dimethyl 2-(2-hydroxy-2methoxypropylidine) malonate and vitexin," Indian Journal of Biotechnology, vol. 10, no. 1, pp. 75-82, 2011.

[29] A. H. Conney, Y. P. Lu, Y. R. Lou, and M. T. Huang, "Inhibitory effects of tea and caffeine on UV-induced carcinogenesis: relationship to enhanced apoptosis and decreased tissue fat," European Journal of Cancer Prevention, vol. 2, pp. 28-36, 2002. 
[30] C. Ioannides and V. Yoxall, "Antimutagenic activity of tea: role of polyphenols," Current Opinion in Clinical Nutrition and Metabolic Care, vol. 6, no. 6, pp. 649-656, 2003.

[31] A. M. Bode and Z. Dong, "Signal transduction pathways: targets for green and black tea polyphenols," Journal of Biochemistry and Molecular Biology, vol. 36, no. 1, pp. 66-77, 2003.

[32] K. S. Kumar, N. Sastry, H. Polaki, and V. Mishra, "Colon cancer prevention through probiotics: an over view," Journal of Cancer Science and Therapy, vol. 7, pp. 081-092, 2015.

[33] R. Jayabalan, S. Marimuthu, and K. Swaminathan, "Changes in content of organic acids and tea polyphenols during kombucha tea fermentation," Food Chemistry, vol. 102, no. 1, pp. 392-398, 2007.

[34] R. Vijayaraghavan, M. Singh, P. V. L. Rao et al., "Sub-acute (90 days) oral toxicity studies of Kombucha tea," Biomedical and Environmental Sciences, vol. 13, no. 4, pp. 293-299, 2000.

[35] N. K. Nguyen, N. T. N. Dong, P. H. Le, and H. T. Nguyen, "Evaluation of the glucuronic acid production and other biological activities of fermented sweeten- black tea by Kombucha layer and the co-culture with different Lactobacillus Sp. strains," International Journal of Modern Engineering Research, vol. 4, no. 5, pp. 12-17, 2014.

[36] Y. Shebis, D. Iluz, Y. Kinel-Tahan, Z. Dubinsky, and Y. Yehoshua, "Natural antioxidants: function and sources," Food and Nutrition Sciences, vol. 4, no. 6, pp. 643-649, 2013.

[37] M. W. L. Koo and C. H. Cho, "Pharmacological effects of green tea on the gastrointestinal system," European Journal of Pharmacology, vol. 500, no. 1-3, pp. 177-185, 2004.

[38] E. A. Adewusi and A. J. Afolayan, "A review of natural products with hepatoprotective activity," Journal of Medicinal Plants Research, vol. 4, no. 13, pp. 1318-1334, 2010.

[39] R. Jayabalan, S. Baskaran, S. Marimuthu, K. Swaminathan, and S. E. Yun, "Effect of kombucha tea on aflatoxin $B_{1}$ induced acute hepatotoxicity in albino rats-prophylactic and curative studies," Journal of Applied Biological Chemistry, vol. 53, no. 4, pp. 407416, 2010.

[40] N. K. Ibrahim, "Possible protective effect of Kombucha Tea Ferment on cadmium chloride induced liver and kidney damage in irradiated rats," World Academy of Science, Engineering and Technology, vol. 55, pp. 1097-1102, 2011.

[41] S. Bhattacharya, R. Gachhui, and P. C. Sil, "Hepatoprotective properties of kombucha tea against TBHP-induced oxidative stress via suppression of mitochondria dependent apoptosis," Pathophysiology, vol. 18, no. 3, pp. 221-234, 2011.

[42] J. Abshenas, A. Derakhshanfar, M. H. Ferdosi, and S. Hasanzadeh, "Protective effect of kombucha tea against acetaminophen-induced hepatotoxicity in mice: a biochemical and histopathological study," Comparative Clinical Pathology, vol. 21, no. 6, pp. 1243-1248, 2012.

[43] Y. Wang, B. Ji, W. Wu et al., "Hepatoprotective effects of kombucha tea: identification of functional strains and quantification of functional components," Journal of the Science of Food and Agriculture, vol. 94, no. 2, pp. 265-272, 2014.

[44] T. I. Jeon, S. G. Hwang, N. G. Park et al., "Antioxidative effect of chitosan on chronic carbon tetrachloride induced hepatic injury in rats," Toxicology, vol. 187, no. 1, pp. 67-73, 2003.

[45] G. S. Murugesan, M. Sathishkumar, R. Jayabalan, A. R. Binupriya, K. Swaminathan, and S. E. Yun, "Hepatoprotective and curative properties of Kombucha tea against Carbon tetrachloride-induced toxicity," Journal of Microbiology and Biotechnology, vol. 19, no. 4, pp. 397-402, 2009.
[46] T. Pauline, P. Dipti, B. Anju et al., "Studies on toxicity, anti-stress and hepato-protective properties of Kombucha tea," Biomedical and Environmental Sciences, vol. 14, no. 3, pp. 207-213, 2001.

[47] M. Sai Ram, B. Anju, T. Pauline et al., "Effect of Kombucha tea on chromate(VI)-induced oxidative stress in albino rats," Journal of Ethnopharmacology, vol. 71, no. 1-2, pp. 235-240, 2000.

[48] A. Aloulou, K. Hamden, D. Elloumi et al., "Hypoglycemic and antilipidemic properties of Kombucha tea in alloxan-induced diabetic rats," BMC Complementary and Alternative Medicine, vol. 12, no. 1, article 63, 2012.

[49] C. Vicente, B. Sebastián, B. Fontaniella, A. Márquez, L. X. Filho, and M.-E. Legaz, "Bioskin as an affinity matrix for the separation of glycoproteins," Journal of Chromatography A, vol. 917, no. 1-2, pp. 55-61, 2001.

[50] D. Banerjee, S. A. Hassarajani, B. Maity, G. Narayan, S. K. Bandyopadhyay, and S. Chattopadhyay, "Comparative healing property of kombucha tea and black tea against indomethacininduced gastric ulceration in mice: possible mechanism of action," Food and Function, vol. 1, no. 3, pp. 284-293, 2010.

[51] N. Khan and H. Mukhtar, "Tea and health: studies in humans," Current Pharmaceutical Design, vol. 19, no. 34, pp. 6141-6147, 2013.

[52] Food safety assessment of Kombucha tea recipe and food safety plan. Food Issue, Notes from the Field, BC Centre for Disease Control, An Agency of the Provincial Health Services Authority, http://www.bccdc.ca/resource-gallery/Documents/Educational \%20Materials/EH/FPS/Food/kombuchal.pdf.

[53] A. S. Kole, H. D. Jones, R. Christensen, and J. Gladstein, "A case of Kombucha tea toxicity," Journal of Intensive Care Medicine, vol. 24, no. 3, pp. 205-207, 2009.

[54] E. Ernst, "A systemic review of the clinical evidence," Research in Complementary medicine, vol. 10, no. 2, pp. 85-87, 2003.

[55] R. Srinivasan, S. Smolinske, and D. Greenbaum, "Probable gastrointestinal toxicity of Kombucha tea: is this beverage healthy or harmful?" Journal of General Internal Medicine, vol. 12, no. 10, pp. 643-644, 1997.

[56] Z. Kovacevic, G. Davidovic, J. Vuckovic-Filipovic, M. A. Janicijevic-Petrovic, K. Janicijevic, and A. Popovic, "A toxic hepatitis caused the kombucha tea-case report," Macedonian Journal of Medical Sciences, vol. 7, no. 1, pp. 128-131, 2014.

[57] F. Bolle, W. Brian, D. Petit, K. Boutakhrit, G. Feraille, and J. Van Loco, "Tea brewed in traditional metallic teapots as a significant source of lead, nickel and other chemical elements," Food Additives and Contaminants Part A, vol. 28, no. 9, pp. 12871293, 2011.

[58] T. G. Phan, J. Estell, G. Duggin, I. Beer, D. Smith, and M. J. Ferson, "Lead poisoning from drinking Kombucha tea brewed in a ceramic pot," Medical Journal of Australia, vol. 169, no. 11-12, pp. 644-646, 1998.

[59] F. A. Durazo, C. Lassman, S. H. B. Han et al., "Fulminant liver failure due to usnic acid for weight loss," The American Journal of Gastroenterology, vol. 99, no. 5, pp. 950-952, 2004.

[60] L. K. Massey, H. Roman-Smith, and R. A. L. Sutton, "Effect of dietary oxalate and calcium on urinary oxalate and risk of formation of calcium oxalate kidney stones," Journal of the American Dietetic Association, vol. 93, no. 8, pp. 901-906, 1993.

[61] S. C. Smolinske, "Herbal product contamination and toxicity," Journal of Pharmacy Practice, vol. 18, no. 3, pp. 188-208, 2005.

[62] P. C. Sherertz, Acetic Acid, Division of Health Hazards Control, Virginia Department of Health, 2015, http://www.vdh.virginia 
.gov/epidemiology/DEE/PublicHealthToxicology/documents/ pdf/aceticacid.PDF.

[63] FAO nutrition meetings, report series no. $40 \mathrm{~A}, \mathrm{~B}, \mathrm{C} \mathrm{WHO} /$ Food add./67.29, Joint FAO/WHO Expert Committee on Food Additives which met at Rome, 13-20 December, 1965 Geneva, 11-18 October, 1966, http://www.inchem.org/documents/jecfa/ jecmono/40abcj37.htm.

[64] FRC code of Federal Regulations, Title 21, Vol. 3, https://www .accessdata.fda.gov/scripts/cdrh/cfdocs/cfcfr/CFRSearch.cfm? $\mathrm{fr}=184.1061$.

[65] Material Safety Data Sheet, 2009, http://www.dogee.org/lab/ chemicals/915.pdf.

[66] International Food Standards, World Health Organization, and Food and Agriculture Organization of the United Nations, "Cordex Alimentarius, Cordex Stan 192-1995," 2015.

[67] Material Safety Data Sheet, 2013, http://www.sciencelab.com/ msds.php?msdsId=9923494.

[68] Oxalic Acid, Summary Report, EMEA/MRL/891/03-FINAL, Committee for Veterinary Medicinal Products, The European Agency for the Evaluation of Medicinal Products, Veterinary Medicines and Inspections, 2003.

[69] Dietary Reference Intakes (DRIs): Estimated Average Requirements, United States National Academy of Sciences, Washington, DC, USA, 2015.

[70] J. Doull, C. D. Klaassen, and M. D. Amdur, Casarett and Doull's Toxicology, Macmillan Publishers, New York, NY, USA, 2nd edition, 1980.

[71] Science Lab, Material Safety Data Sheet, Science Lab, 2013, http://www.sciencelab.com/msds.php? msdsId=9922768.

[72] J. Mrdanović, G. Bognadović, D. Cvetković, A. Velićanski, and D. Četojević-Simin, "The frequency of sister chromatid exchange and micronuclei in evaluation of cytogenetic activity of Kombucha on human peripheral blood lymphocytes," Archive of Oncology, vol. 15, no. 3-4, pp. 85-88, 2007.

[73] C. Shenoy, "Hypoglycemic activity of bio-tea in mice," Indian Journal of Experimental Biology, vol. 38, no. 3, pp. 278-279, 2000.

[74] A. M. Hartmann, L. E. Burleson, A. K. Holmes, and C. R. Geist, "Effects of chronic kombucha ingestion on open-field behaviors, longevity, appetitive behaviors, and organs in c57bl/6 mice: a pilot study," Nutrition, vol. 16, no. 9, pp. 755-761, 2000.

[75] A. Morshedi, M. H. Dashti, M. H. Mosaddegh, A. Rafati, and A. S. Salami, "The chronic effect of Kombucha tea consumption on weight loss in diabetic rats," Journal of Medicinal Plants, vol. 5, no. 2, pp. 17-22, 2006.

[76] K. Cavusoglu and P. Guler, "Protective effect of Kombucha mushroom (KM) tea on chromosomal aberrations induced by gamma radiation in human peripheral lymphocytes in vitro," Journal of Environmental Biology, vol. 31, no. 5, pp. 851-856, 2010. 

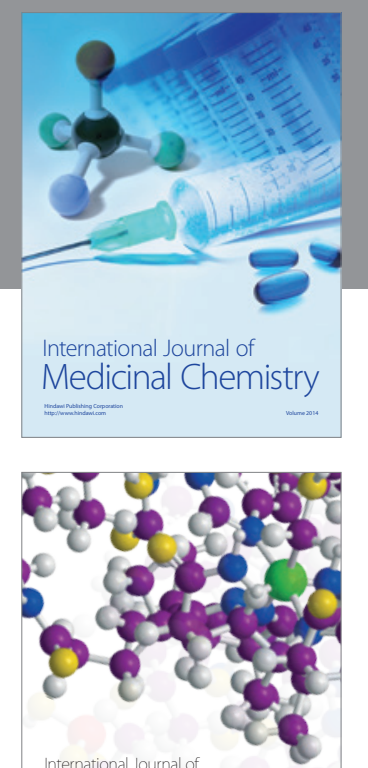

\section{Carbohydrate} Chemistry

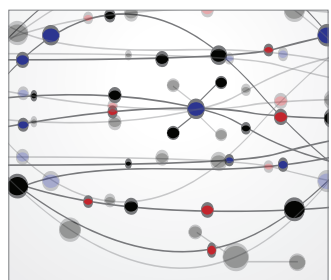

The Scientific World Journal
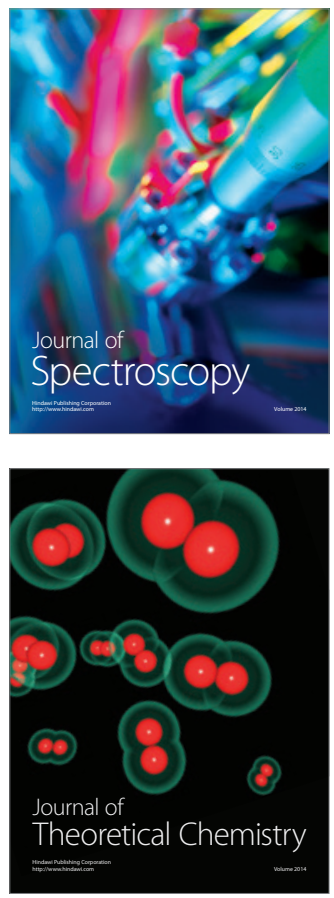
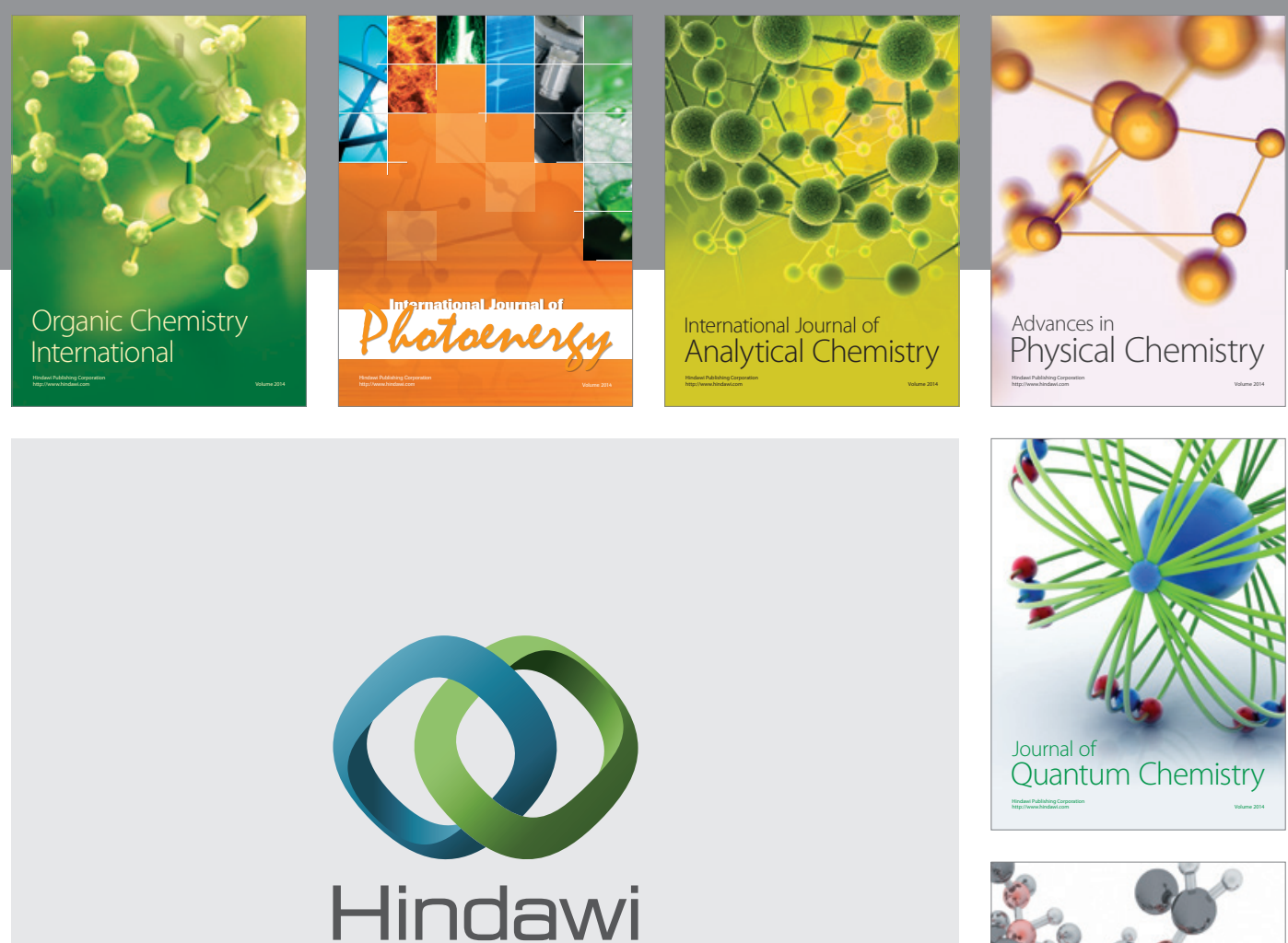

Submit your manuscripts at

http://www.hindawi.com

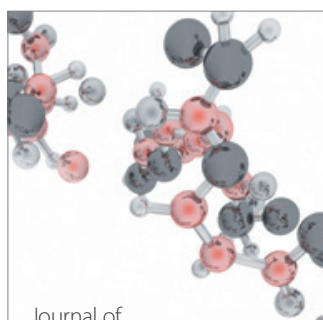

Analytical Methods

in Chemistry

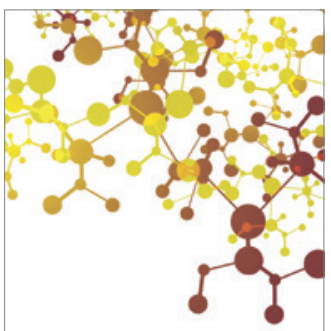

Journal of

Applied Chemistry

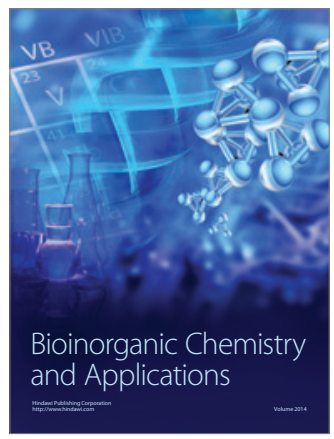

Inorganic Chemistry
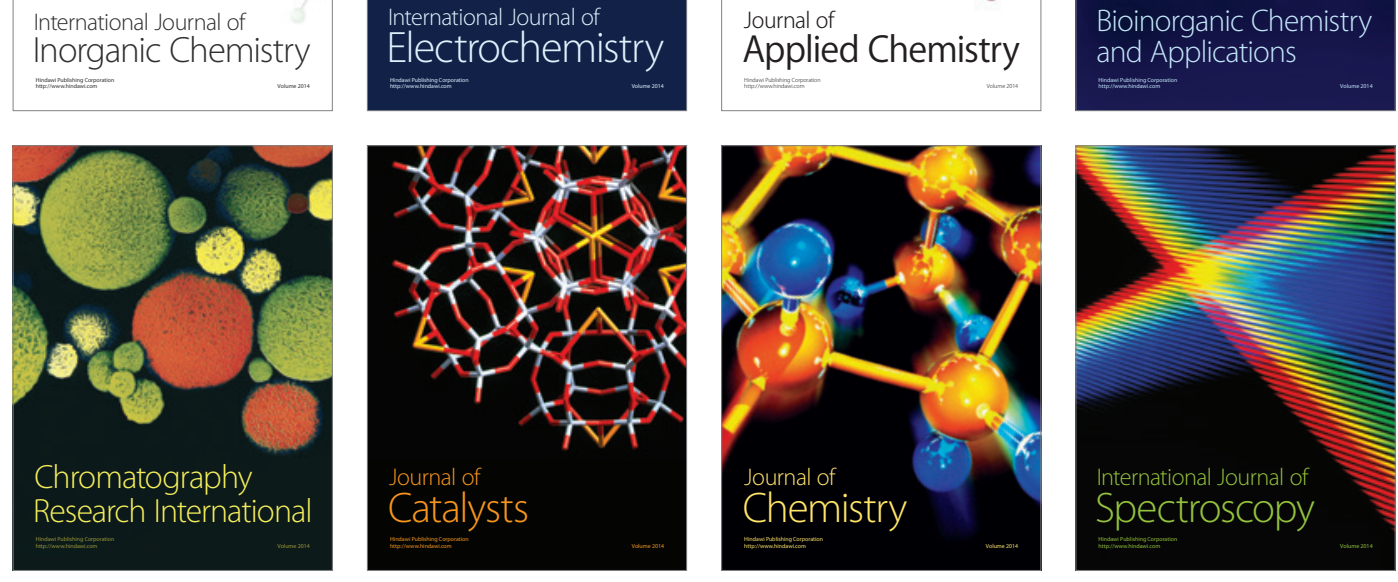